\title{
Imitation Modeling of Social Investments in Early Childhood Education.
}

\author{
Katrīne Kūkoja \\ Institute of Social, Economic and Humanities Research \\ (HESPI) \\ Vidzeme University of Applied Sciences (ViA) \\ Valmiera, Latvia \\ katrine.kukoja@va.lv
}

\begin{abstract}
Previous researches show, that social investments in early childhood (until age of 6) are very important, and one of the main types of social investment in this period of time is quality early childhood education and care services (henceforth - ECEC services). Social investments in early childhood have the highest return in human capital, especially for disadvantaged groups of the society. Literature suggests that positive effect of available and qualitative ECEC services can be observed in many areas of life, for example, through improved education indicators, increased participation of the women in the labour market, increased work productivity, higher birth rates, etc. However, the attendance of ECEC services varies considerably between different European Union (henceforth - EU) countries.
\end{abstract}

The aim of this paper is to analyze social investment effect in early childhood in EU countries with high (Denmark), medium (Latvia) and low (Croatia) ECEC service attendance rates, so to find out if and how ECEC service attendance rate in these countries influences such indicators as rate of early leavers from education and training, school graduation rates and female employment rate. To see how situation may change due to the ECEC attendance rate changes in each country analyses was be carried out with imitation model options.

This article describes the imitation model, which provides an opportunity to analyze the current situation and compare social investments between different EU countries. The model is designed using ISEE system STELLA MODELING and Imitation Software environment, and it is governed by the criteria that are based on literature studies, as well as analyses of statistic data. An additional benefit is that this model can be adjusted and used to evaluate other countries social investment tendencies as well.

Research results show, that not all indicators that have been positively connected with ECEC attendance rate in previous studies have been positively influenced by ECEC attendance rate in chosen case study countries. Analyses showed that only in Croatia positive connections can be observed when it comes to all three indicators. Further studies should be carried out on this topic to get a deeper understanding on ECEC attendance rate effect on these and other indicators, that in the previous studies have been positively linked with ECEC attendance rate.

Keywords - Child development, Early childhood education, Female employment, Social investment.

\author{
Feliciana Rajevska \\ Institute of Social, Economic and Humanities Research \\ (HESPI) \\ Vidzeme University of Applied Sciences (ViA) \\ Valmiera, Latvia \\ feliciana.rajevska@va.lv
}

\section{INTRODUCTION}

Social investment is about investing in people. It means policies designed to strengthen people's skills and capacities and support them to participate fully in employment and social life. One of the main policy areas of social investment is quality childcare [1]. Over the years literature and previous studies have shown that social investments in early age (until age of 6) has the highest return in the human capital (see Fig. $1,[2])$ and their effect, mainly through quality childcare, can be observed in many areas of life both in long and short term, including [2], [3], [4], [5], [6], [7], [8], [9], [10]:

RETUAN TO A UNIT DOLLAR INVESTED ARE HIGHEST IN EARLIEST YEARS

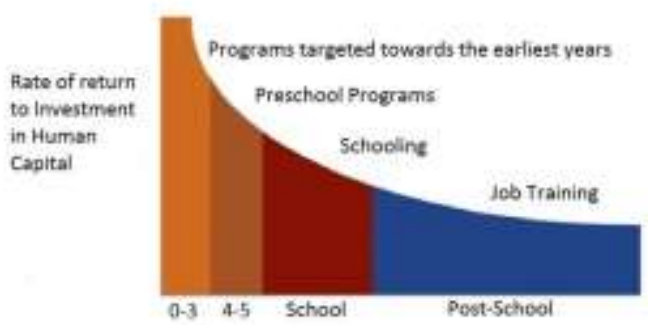

Fig. 1. Return to a dollar invested in different levels of education [2]

education outcome increase (lower rate of early leavers from education and training, higher school graduation rates, etc.)

- $\quad$ social economic outcome increase (higher fertility rate and increased female workforce participation, etc.);

- $\quad$ exchequer returns increase (higher tax returns, etc.)

- long-term economic outcome increase (increased earnings and labour-force participation, etc.)

- $\quad$ health, social well-being and welfare dependency reduction (reduction in expenditures for the child welfare system, etc.) 
crime rate reduction (reductions in criminal justice system expenditures for youth and adult crime, etc.)

Previous researches show that indicators mentioned above are positively connected with early childhood education and care service (henceforth - ECEC) attendance rate, that is why, within this article three of these indicators were selected randomly - rate of early leavers from education and training, school graduation rates and female (mothers') employment rate, to see if these tendencies take place in chosen case study countries as well. Literature shows that ECEC services have as much to do with promoting mothers' employment as it does with improving development of young children [2],[7],[8]. Researches show that attending ECE classes helped pupils to better prepare for school and increases possibility for a child to graduate and gain better education that will later on help them to succeed in work life [2],[3],[8].

Importance of social investment in early childhood has been stressed in both Latvian, as well as European Union (henceforth - EU) planning documents. One of the policy priorities defined by both the European Commision and the European Parliament in order to meet the Europe2020 targets is to "ensure universal provision of ECEC" [11], [12].

Since the main form of social investment in this period of life is accessible and qualitative ECEC services, authors have analysed exactly this form of investments in selected country case studies - Denmark, Latvia and Croatia. These countries were selected based on the ECEC attendance rate one EU country with high, average and low ECEC service attendance rate were chosen. Authors chose this approach to have wider view of social investment effect in different EU countries. Eurostat data show that in $201698,1 \%$ children in Denmark, $95.5 \%$ children in Latvia and $75.1 \%$ children in Croatia aged between 4 and the age of starting compulsory education were in early childhood education [13]. When it comes to children before age of four (including), ECEC attendance rate is considerably lower. In $201673.44 \%$ of children until age of four (including) attended ECEC in Denmark, while in Latvia it was $54.71 \%$ and in Croatia $35.64 \%$. As we can see, if compared, ECEC attendance rate in Denmark is the highest, in Croatia the lowest, while in Latvia it has been relatively average [14], [15].

The aim of this research was to see if and how availability of ECEC over the past years has influenced selected indicators in three EU countries, as well as to see how situation may change due to the ECEC service attendance rate changes in each country. To do that simulation model was created.

\section{MATERIALS AND METHODS}

To achieve aim of this research analysis of previous researches and policy documents was performed, as well as historical data analysis of ECEC attendance rate and chosen indicators - women employment rate, rate of early leavers from education and training and upper-secondary education graduation rate in selected countries in period from 2013 to 2017, with exception in case of Croatia, since data only about period from 2013 to 2016 were available. Data were selected and analyzed in five (in case of Croatia - four) year period due to the fact that there is a lack of open-access data that could be used for comparison between the countries. That is why it was not possible to analyze longer period of time. In many cases data were not available or they were structured differently between countries.

To get a wider prospect, case studies in three countries with different ECEC attendance rates were carried out. EU countries with high - Denmark, medium - Latvia, and relatively low - Croatia, ECEC service attendance rates were chosen.

Imitation model was developed using ISEE system STELLA MODELING and Imitation Software environment to better illustrate, analyze and compare the situations in selected countries. Based on historical statistic data about ECEC attendance rate and chosen indicators in selected countries, model has the possibility to generate how each of the above mentioned indicators will change if ECEC attendance rate will change in the each country.

TABLE I. ECEC ATTENDANCE RATE AND SELECTED INDICATOR AVERAGE VALUES IN DENMARK, LATVIA AND CROATIA

\begin{tabular}{|c|c|c|c|c|}
\hline & $\begin{array}{l}\text { ECEC } \\
\text { attendanc } \\
\text { e rate }\end{array}$ & $\begin{array}{l}\text { Gradua- } \\
\text { tion rate }\end{array}$ & $\begin{array}{l}\text { Rate of } \\
\text { early } \\
\text { leavers } \\
\text { from } \\
\text { education } \\
\text { and } \\
\text { training }\end{array}$ & $\begin{array}{l}\text { Women } \\
\text { employ- } \\
\text { ment }\end{array}$ \\
\hline DK & 73.72 & 11.3 & 7.92 & $77.97^{*}$ \\
\hline $\mathbf{L V}$ & 52.30 & $8.5^{*}$ & $9.36^{*}$ & 65.78 \\
\hline HR & 34.02 & 9.67 & 3.23 & 61.33 \\
\hline
\end{tabular}

Model is static, determined, based on discrete events and divided into three sectors, where each of the sectors represents one of the countries.

Before date usage in model, data were analyzed and edited using SPSS Software to see if these data are statistically relevant, usable and valid, as well as to see if correlations between ECEC attendance rate and selected indicators in all three countries can be observed in the researched period.

Since the One-Sample Kolmogorov-Smirnov Test at significance level 0.05 confirmed that with $95 \%$ probability ECEC attendance rate, as well as women's employment, graduation rate and rate of early leavers from education and training in analyzed period corresponds to normal data distribution in Denmark, Croatia and Latvia, the average values of the indicators where used in this model as status quo values, see table I [14], [15].

\section{Model description}

At the interface level of the Social investment effect simulation model, there are two buttons for easy operation of the model and six displays for results that show how indicator values change, if we change ECEC attendance rate. The button "Run" provides the opportunity to start the data processing of components after the input of variable data. The button "Restore Sliders" is made for user's convenience. At the model-making level the current ECEC attendance rate 
Kükoja et al. Imitation Modeling of Social Investments in Early Childhood Education and indicator parameters are entered, then this button allows resetting original parameters (status quo) after the changes are made. In Fig. 2 we can see the model interface view at status quo position.

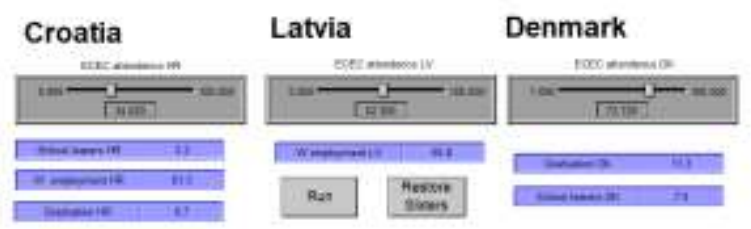

Fig. 2. Model interface view-status quo position

\section{RESULTS AND DISCUSSION}

TABLE II. ECEC ATTENDANCE RATE UNTIL AGE OF 4 (INCLUDING) IN DENMARK, LATVIA AND CROATIA ( 2013-2017/2016).

\begin{tabular}{|l|r|r|r|r|l|}
\hline & $\mathbf{2 0 1 3}$ & $\mathbf{2 0 1 4}$ & $\mathbf{2 0 1 5}$ & \multicolumn{1}{|l|}{$\mathbf{2 0 1 6}$} & $\mathbf{2 0 1 7}$ \\
\hline DK & 74.68 & 74.76 & 73.82 & 73.44 & 71.89 \\
\hline HR & 32.68 & 33.45 & 34.31 & 35.64 & \\
\hline LV & 49.39 & 50.32 & 52.64 & 54.71 & 54.44 \\
\hline
\end{tabular}

When we analyse social investment in early childhood it is important to look at the ECEC service availability, especially in the early age. As we saw in the previous selection - while the ECEC attendance rate for children aged between 4 and the age of starting compulsory education were relatively high and didn't have significant differences between selected case study countries (especially Latvia and Denmark), when it came to younger children the results were not so positive. Therefore authors decided that in this article data regarding ECEC attendance before age of 4 (including) will be used.

As we can see in the table II attendance rate of ECEC until age of 4 (including) has been the highest in Denmark. However we can see a tendency of ECEC attendance rate to increase in Latvia and Croatia since 2013, while in Denmark the rate has been steady with little decrease in 2017 [14], [15].

As we can see in the table III [14], [15], despite the previous research results, not all indicators correlated positively with the ECEC attendance rate in the case study countries. When it comes to Latvia, only women employment in the period from 2013 till 2017 had a positive correlation with ECEC attendance rate. In Denmark situation, we can see that there is a positive correlation between ECEC attendance rate and women employment, as well as relatively average negative correlation between ECEC attendance rate and rate of early leavers from education and training. While only in the Croatia ECEC attendance rate has had positive impact on all three indicators, although the correlations were average when it came to women employment, and little bit above average when it came to graduation rates and rate of early leavers from education and training.
TABLE III. CORRELATION BETWEEN RVRV ATTENDANCE RATE AND SELECTED INDICATORS IN DENMARK, LATVIA AND CROATIA IN $2003-2017$

\begin{tabular}{|l|l|l|l|}
\hline \multirow{2}{*}{$\begin{array}{c}\text { ECEC } \\
\text { attendance } \\
\text { rate }\end{array}$} & $\begin{array}{c}\text { Women } \\
\text { employment }\end{array}$ & $\begin{array}{c}\text { Indicators } \\
\text { Graduation } \\
\text { rate }\end{array}$ & $\begin{array}{c}\text { Rate of early } \\
\text { leavers from } \\
\text { education and } \\
\text { training }\end{array}$ \\
\hline DK & 0.941 & $-0.638^{*}$ & -0.546 \\
\hline LV & 0.885 & $-0.893^{*}$ & $0.073^{*}$ \\
\hline HR & 0.564 & 0.602 & -0.704 \\
\hline
\end{tabular}

* Won't be used in the model

TABLE IV. ECEC ATTENDANCE RATE AND SELECTED FACTOR STATISTIC DATA IN 2015 IN DENMARK, LATVIA AND CROATIA.

\begin{tabular}{|l|l|l|l|l|}
\hline & $\begin{array}{l}\text { ECEC } \\
\text { attendance } \\
\text { rate }\end{array}$ & $\begin{array}{l}\text { Rate of } \\
\text { early leavers } \\
\text { from } \\
\text { education } \\
\text { and training }\end{array}$ & $\begin{array}{l}\text { Women } \\
\text { employ- } \\
\text { ment }\end{array}$ \\
\hline DK & 73.82 & 11.24 & 7.92 & 76.88 \\
\hline LV & 52.64 & 9 & 9.36 & 64.13 \\
\hline HR & 34.31 & 9.277 & 3.23 & 61.87 \\
\hline
\end{tabular}

Since analyses of the data didn't show positive correlations between ECEC attendance rate and graduation rate in upper secondary level of education in Latvia and Denmark, as well as negative correlation with rate of early leavers from education and training in Latvia, these indicators were not included in the model in the case of Latvia and Denmark. But authors suggest that further studies regarding these factors and the research results should be carried out. All the other indicators were included in the model.

Despite the fact that not all of the chosen indicators correlated positively with ECEC attendance in all countries, Denmark still showed best performance in almost all indicators, except in the case of rate of early leavers from education and training. As we can see in table I and IV, lowest school leavers rate in researched period was in Croatia. Croatia showed better performance then Latvia in two out of 3 indicators - rate of early leavers from education and training and upper-secondary level of education graduation rate. In table IV situation in year 2015 can be observed [14], [15].

As we can see in the Fig. 2, where model interface view at status quo position is shown, average ECEC attendance rate in Croatia in researched period was $34,02 \%$ for children until age of four (including), in Latvia - 52,3\% and in Denmark $-73.72 \%$. Average rate of early leavers from education and training was the lowest in Croatia $3.23 \%$ and in Denmark it is $7.92 \%$. Data for the second indicator, women employment rate in Croatia was $61.3 \%$ and in Latvia $-65.8 \%$. For the last selected indicator - graduation rate in upper-secondary education, that was included in the model only for Denmark and Croatia, the average rate was $9,7 \%$ in Croatia and $11,3 \%$ in Denmark. The developed simulation model not only helps to analyze and compare social investments effect on different indicators, but also gives an opportunity to see how changes in ECEC attendance rate in each country may influence selected indicators. 
Kükoja et al. Imitation Modeling of Social Investments in Early Childhood Education

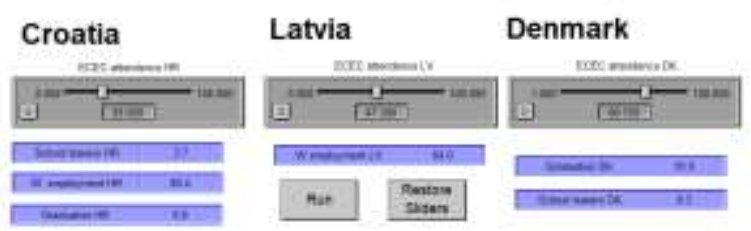

Fig. 3. Model interface view- second case where ECEC attendance decreasd by $5 \%$

During this study, the simulation model verification was carried out to avoid gaps in the model. Two case scenarios were simulated using this imitation model - the case when ECEC attendance rate decreases for $5 \%$ in each country and the case where it increases for $3 \%$.

In the first case simulation model shows that by decreasing ECEC attendance by $5 \%$ it negatively influences all of the selected indicators in case study countries. As we can see in Fig. 3 in Croatia case data shows that decrease in ECEC attendance can increase school leaver rate for averagely $0.5 \%$, women employment for $0.9 \%$ and graduation rate could decrease for $0.7 \%$. When it comes to Latvia, simulation shows that with these changes women employment rate could drop for $1.8 \%$, since the correlation between these indicators were relatively strong. As for the Denmark, based on the simulation results, decrease in the ECEC attendance rate could lower graduation rate for $0.4 \%$, and increase school leaver's rate for $0.4 \%$

In the second case simulation model shows that by increasing ECEC attendance for 3\% it positively influences all of the selected indicators in three countries. As we can see in the Fig.4 this little increase in attendance rate can positively influence many areas of life. For example, women employment rate in Croatia could be increased for $0.6 \%$ and in Latvia for $1 \%$, graduation rates increased for $0,2 \%$ in Denmark to $0.3 \%$ in Croatia, and rate of early leavers of education and training decreased for $0.2 \%$ in Denmark to $0.2 \%$ in Croatia.

However, it is necessary to take into consideration that these simulation results are approximate and are reliable with the condition, that all the other factors that influence these indicators stay the same.
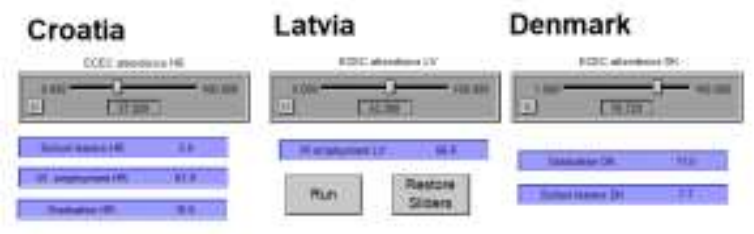

Fig. 4. Model interface view- second case where ECEC attendance increases by $3 \%$

\section{CONCLUSION}

Research results shows that during the last years there has been increase in social investments in early childhood, especially when we look at ECEC service availability- attendance rate increase in Latvia and Croatia. However, despite the fact that attendance rate is the highest in Denmark, we cannot observe increase in it during the last five years. This may be due to the fact that Denmark already has rather high and stable result in this area as outcome of previous investments, but further studies should be carried out concerning this question.

Statistic data show that Denmark has the highest ECEC attendance rate and has been the leader when it comes to women employment and graduation of upper-secondary education, but level of early school leavers has been relatively high in Denmark, even higher than in Croatia, that showed the lowest rate of early leavers from education and training in the period from 2013-2017.

Despite the fact that Latvia has the second highest ECEC attendance rate of the case study countries, only one of the studied indicators showed to be higher in Latvia, then in Croatia - women employment. This may mean that in case of the graduation rate and rate of early school leavers, ECEC attendance doesn't show such an impact in Latvia, and other factors, for example, ECEC quality, may have a stronger impact on these results. Further studies should be carried out in this field.

Research results show that not all indicators that have been positively connected in previous studies with increased ECEC attendance showed positive correlation in Latvia and Denmark. The only country where ECEC attendance showed high or at least average connection with all of the selected indicators was Croatia. In Denmark case positive correlation could not be observed in the case of graduation rate in uppersecondary education level, but in Latvia - in the case of graduation rate and rate of early leavers of education and training.

Research shows that ECEC attendance rate can positively influence child's development and women employment in most of the selected countries, but in case of education attainment (child's development) situation is more complicated, so authors recommend to carry more studies in longer period of time and with more indicators, to have even wider view on the situation of investment effect.

As a result of this research, a simulation model in the field of ECEC effect on child's development and women employment was developed. Such approach for the determination of the ECEC effect on different indicators, that have previously been positively linked to ECEC attendance rate, has not been used so far before. This model gives a possibility to look at the effect of ECEC attendance on different indicators in different EU countries.

\section{ACKNOWLEDGMENTS}

Research has been conducted within the project "Values in Action: promotion of responsible, secure and educated civil society in Latvia through research and model development" (Project No. VPP-IZM-2018/1-0013). 
Environment. Technology. Resources. Rezekne, Latvia

Proceedings of the 12th International Scientific and Practical Conference. Volume II, 200-204

REFERENCES

[1] European Commision, "Home page - European Commision," February 2019. [Online]. Available: https://ec.europa.eu/social/main.jsp?catId=1044\&langId=en [Accessed Jan. 28, 2019]

[2] J. J. Heckman, ,Schools, skills, and synapses,” Economic Inquiry, vol. 46, no. 3, p. 289-324, 2008 [Online] Available: NBER, https://www.nber.org/papers/w14064 [Accessed June 1, 2018], DOI: $10.3386 / \mathrm{w} 14064$

[3] R.M. Jacinta and K.S. Jacinta, "Impact of Early Childhood Education on Pupils' Learning in Primary Schools in Kenya," Global Journal of Educational Studies, vol. 1, no. 1, p. 52-61, May, 2015 [Online] Available: Macrothink Institute, http://www.macrothink.org/journal/index.php/gjes/article/view/768 6 [Accessed $\quad$ Nov. 20, 2018], http://dx.doi.org/10.5296/gjes.v1i1.7686

[4] A. J. Reynolds, J. A. Temple, B. A. White, S. R. Ou and D. L. Robertson, "Age-26 Cost-Benefit Analysis of the Child-Parent Center Early Education Program," Child Development, vol 82, no. 1, p. 379-404, January-February 2011 [Online]. Available: NCBI, https://www.ncbi.nlm.nih.gov/pmc/articles/PMC3817956/ [Accessed May 9, 2018], https://doi.org/10.1111/j.14678624.2010.01563.x

[5] Education, Audiovisual and Culture Executive Agency and Eurydice, "Early Childhood Education and Care in Europe: Tackling Social and Cultural Inequalities," Education, Audiovisual and Culture Executive Agency and Eurydice, p. 188, 2009 [Online]. Available: https://publications.europa.eu/en/publication-detail//publication/83f56fb3-62f0-440e-b646-c782f2abef18/language-lv [Accessed: Dec. 20, 2018].

[6] T. Havnes and M. Mogstad, "No Child Left Behind Universal Child Care and Children's Long-Run Outcomes," American Economic Journal: Economic Policy, vol. 3, no. 2, p. 97-129, May 2011 [Online]. Available:

SSB https://www.ssb.no/a/publikasjoner/pdf/DP/dp582.pdf [Accessed Dec. 20, 2018], DOI: 10.1257/pol.3.2.97
[7] Janna van Belle, "Early Childhood Education and Care (ECEC) and its long-term effects on educational and labour market outcomes," Janna van Belle, p.33, 2016. [Online] Available: https://www.rand.org/pubs/research_reports/RR1667.html [Accessed: Jan. 12, 2019], https://doi.org/10.7249/RR1667

[8] N. Morel, B. Palier and J. Palme, Towards a Social Investment Welfare State?: Ideas, Policies and Challenges The Policy press, Great Britain, 2012

[9] Editor-in chief F. Rajevska, Turns of Social Policy Transformation in post-crisis years, National research program EKOSOC_LV, project 5.2.6. LU, RSU, ViA, Riga, 2018.

[10] F. Campbell, G. Conti, J.J. Heckman, S.H. Moon, R. Pinto, E. Pungello, Y. Pan, "Early Childhood Investments Substantially Boost Adult Health," Science, vol. 343, issue 6178, p. 1478-1485, March 2014 [Online] Available: Science, http://science.sciencemag.org/content/343/6178/1478.long [Accessed Nov 2, 2018], DOI: $10.1126 /$ science.1248429

[11] European Commission," Early Childhood Education and Care: Providing All Our Children the World of Tomorrow," European Commission, p.9, 2011.[Online]. Available: file:///C:/Users/Lietotajs/Desktop/Downloads/RAND_RR1667.pdf [Accessed: October. 17, 2018].

[12] European Parliament, "Resolution of 12 May 2011 on Early Years Learning in the European Union, 2010/2159/INI," European Parliament, p. 7, 2011.[Online]. Available: https://eurlex.europa.eu/legalcontent/EN/TXT/PDF/?uri=CELEX:52011IP0231\&from=EN [Accessed: October. 17, 2018].

[13] European Commision, "Home page - European Commision," September 2018. [Online]. Available: https: //ec.europa.eu/ eurostat/statistics-explained/index.php/Early_childhood _and_primary_education_statistics [Accessed: Jan, 2019]

[14] Central Statistical Bureau of Latvia, "Home page - Central Statistical Bureau of Latvia," December 2018 [online]Available: http://www.csb.gov.lv/en [Accessed: Jan. 15, 2019]

[15] European Commision, "Home page - European Commision," September 2018. [Online]. Available: https://ec.europa.eu/eurostat/data/database [Accessed: Jan. 15, 2019] 